\title{
An eutrophication model for a lowland river-lake system
}

\author{
A. Gnauck \& B. Luther \\ Brandenburg University of Technology at Cottbus, \\ Department of Ecosystems and Environmental Informatics, Germany
}

\begin{abstract}
Natural and man induced nutrient loads affect the functioning of freshwater ecosystems and restrict various water uses. In particular, internal pollution by nutrient remobilisation from sediment plays an important role in shallow water bodies. A sustainable management of such freshwater ecosystems can be achieved by using simulation models. To forecast the eutrophication process of a shallow river-lake system a modelling and simulation framework was developed including phosphorus remobilisation from sediment. Data are taken from the Lower Havel River. For water quality management decision control strategies based on the limiting nutrient concept and threshold values of LAWA are discussed.
\end{abstract}

Keywords: eutrophication, water quality, modelling, phosphorus remobilisation, optimisation.

\section{Introduction}

Eutrophication of freshwater bodies is characterised by an increase of dissolved nutrients in water bodies, mainly phosphorus, carbon and nitrogen, by excessive growth of plants, mainly algae, and by restricted water uses due to anoxic water conditions as well as by odour problems [1,2]. The eutrophication process of freshwater ecosystems is supported by intensive man-made activities in river basins. Man-made impacts caused a shift from oligotrophic to eutrophic and sometimes to hypertrophic freshwater ecosystems. Now it has become clear, that sediments have been accumulating phosphorus over several decades so that they now function as internal phosphorus sources [3]. Compared with the amount of phosphorus in the pelagic zone of eutrophic lakes, the phosphorus content of the sediment of shallow water bodies is considerable higher. 
Sustainable management decisions to control the quality of freshwater ecosystems can only be achieved by using powerful simulation tools. Water quality models are widespread used for managing eutrophication problems [4]. Some eutrophication models contain optimisation procedures to get optimal results [5]. For a shallow river-lake system a modelling and simulation framework to control the water quality was developed. Time series analysis methods are used for process identification [6]. By means of wavelet analysis interrelations between water quality indicators and sediment could be identified, while [7] developed a single process model describing the phosphorus remobilisation from sediment. As a second step changing water quality levels are simulated by an eutrophication simulator [8] carried out within a MATLAB environment. To get a practicable software tool for simulation and optimisation an eutrophication simulator was coupled with an optimisation tool $[9,10]$. In this paper, optimised simulation results are presented for important water quality indicators such as phytoplankton biomass, phosphate phosphorus, ammonia nitrogen and nitrate nitrogen.

\section{Process identification}

The eutrophication process is stimulated by nutrient remobilisation from sediment supported by meteorological and hydrochemical conditions. Water temperature is one of the most important driving forces in freshwater ecosystems. Therefore, correlations between water temperature and phosphate were studied by time series analysis. In particular, wavelet analysis with a Daubechies wavelet at level 5 [11] was carried out. Fig. 1 shows the details of Daubechies wavelet analysis between both indicators at level 5 .

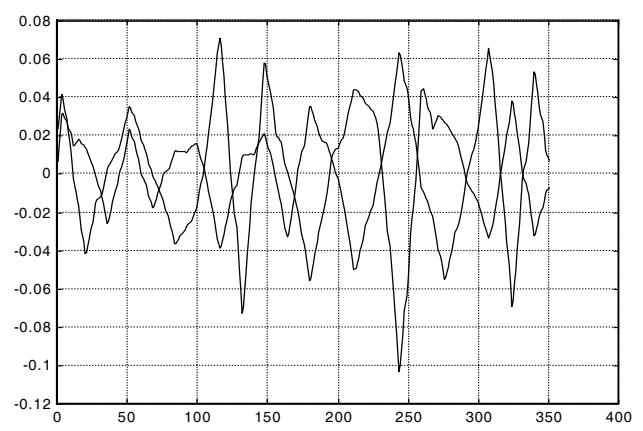

Figure 1: Daubechies wavelet analysis of water temperature and phosphate phosphorus at level 5 .

Heating and cooling of the water is accompanied by an opposite event of phosphate phosphorus because of temperature dependencies of chemical reaction rates. This result was confirmed by residual cross correlations where highest negative values could be found at lag 0 as can be seen from fig. 2 . 


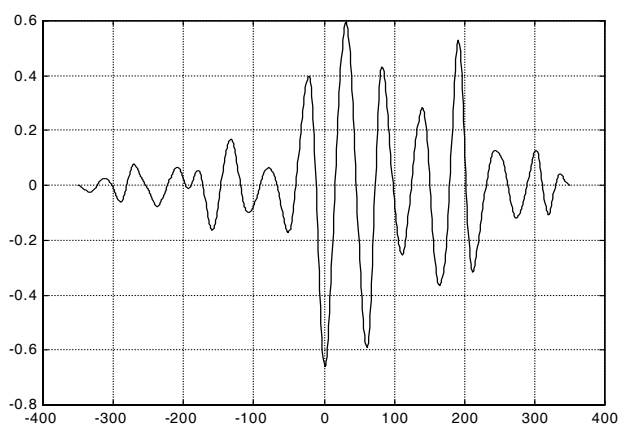

Figure 2: $\quad$ Residual cross-correlation function of level 5.

The process of P-remobilisation can be divided into four phases (table 1).

Table 1: $\quad$ Phases of temperature dependency of phosphate remobilisation.

\begin{tabular}{|l|l|l|}
\hline \multicolumn{1}{|c|}{ WT changes } & \multicolumn{1}{c|}{ WT gradients } & \multicolumn{1}{c|}{ P dynamics } \\
\hline Increase of WT & $\mathrm{f}^{\prime}(\mathrm{WT})>0, \mathrm{f}^{\prime \prime}(\mathrm{WT})>0$ & Storage of phosphate \\
\hline Diminished increase of WT & $\mathrm{f}^{\prime}(\mathrm{WT})>0, \mathrm{f}^{\prime \prime}(\mathrm{WT})<0$ & Start of P-remobilisation \\
\hline Decrease of WT & $\mathrm{f}^{\prime}(\mathrm{WT})<0, \mathrm{f}^{\prime \prime}(\mathrm{WT})<0$ & Increasing P-remobilisation \\
\hline Diminished decrease of WT & $\mathrm{f}^{\prime}(\mathrm{WT})<0, \mathrm{f}^{\prime \prime}(\mathrm{WT})>0$ & Stop of P-remobilisation \\
\hline
\end{tabular}

For modelling the AQUASIM software was used [12]. Fig. 3 shows the model concept.

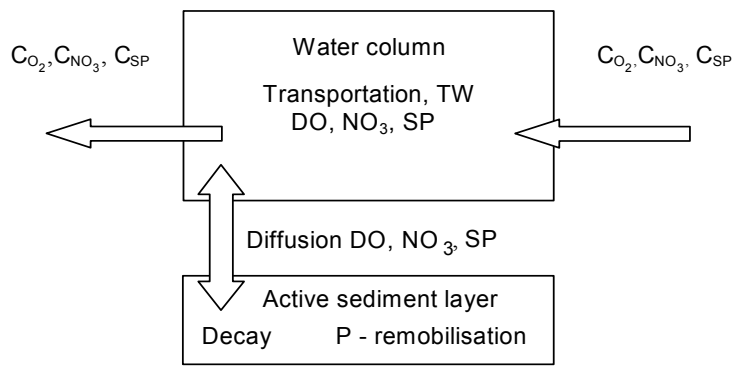

Figure 3: Model concept of P-remobilisation from sediment (SP-soluble phosphorus, DO-dissolved oxygen, NO3-nitrate nitrogen) (modified according to [7]).

The input to each river-lake segment is given by three input boundary conditions for dissolved oxygen, nitrate and soluble phosphorus. The sub-model equation is given by 


$$
\begin{aligned}
\mathrm{dP}_{\mathrm{SED}} / \mathrm{dt}= & (-1)^{\Theta} \cdot \mathrm{phi} \cdot \mathrm{hs}\left(-\mathrm{Dsp} /\left(1-\ln \left(\mathrm{phi}^{2}\right)\right)\left(\mathrm{P}-\left(\mathrm{P}_{\mathrm{SED}} /(\mathrm{hs} \cdot \mathrm{phi})\right)\right) / \mathrm{hs} / 2\right. \\
& +\Theta(\mathrm{cpcrit}-\mathrm{cpEA} / \mathrm{cpcrit}) \cdot(\mathrm{KFe} \mathrm{CpFe}+\mathrm{qp}))
\end{aligned}
$$

with $\Theta=1$, if $\mathrm{CpEA} \leq$ cpcrit, and $\Theta=0$, if CpEA $>$ cpcrit. The parameters are phi - sediment porosity, hs - thickness of active sediment layer (m), Dsp diffusion coefficient of dissolved phosphorus, $\mathrm{P}$ - dissolved phosphorus, $\mathrm{CpFe}-$ iron concentration in pore water, $\mathrm{qp}$ - ratio $\mathrm{P} / \mathrm{Fe}$ of reducible iron, $\mathrm{KFe}$ - iron concentration in pore water with $\mathrm{KFe}=\mathrm{K} 1(\mathrm{TW}) / 36$, cpcrit - critical value of $\mathrm{CpEA}, \mathrm{K} 1(\mathrm{TW})=\mathrm{K} 1(20)^{(0.1 \cdot \lg (2) / \lg (\mathrm{K} 120) \cdot(\mathrm{TEMP}-20)+1)}-$ temperature dependent decay rate of organic material in pore water, $\mathrm{K} 1(20)$ - standardised decay rate organic material in pore water at $20^{\circ} \mathrm{C}, \mathrm{CpO} 2$ - dissolved oxygen concentraqtion in pore water with $\mathrm{CpO} 2=\mathrm{O} 2 / 31,998, \mathrm{CpNO} 3-$ nitrate concentration in pore water with $\mathrm{CpNO} 3=\mathrm{NO} 3 / 14.007, \mathrm{CpEA}-$ electron acceptor concentration in pore water with $\mathrm{CpEA}=2 \mathrm{CpO} 2+5 \mathrm{CpNO} 3$.

\section{The eutrophication simulator HavelMod}

To simulate the eutrophication process in shallow water bodies a stationary 1Dmodel was developed within the MATLAB environment. Fig. 4 shows the model concept.

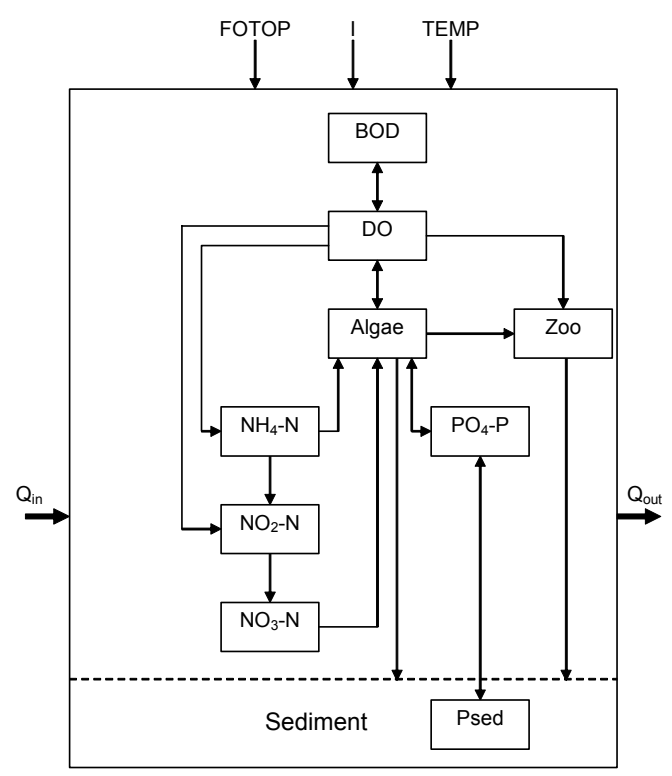

Figure 4: Conceptual model of the eutrophication simulator.

Model state variables are given by the water quality indicators phytoplankton (algae), zooplankton (zoo), orthophosphate phosphorus $\left(\mathrm{PO}_{4}-\mathrm{P}\right)$, ammonia nitrogen $\left(\mathrm{NH}_{4}-\mathrm{N}\right)$, nitrite nitrogen $\left(\mathrm{NO}_{2}-\mathrm{N}\right)$, nitrate nitrogen $\left(\mathrm{NO}_{3}-\mathrm{N}\right)$ as well as 
by dissolved oxygen (DO) and biochemical oxygen demand (BOD). The phosphorus remobilisation process from sediment was included in the phosphorus balance equation. Detailed descriptions of model equations, parameters, site constants and system specific parameters are presented in [10]. $\mathrm{Q}_{\text {in }}$ and $\mathrm{Q}_{\text {out }}$ describe the discharges into and out of the river segment or lake under consideration. External driving forces are photoperiod (FOTOP), solar radiation (I) and water temperature (TEMP). Model equations are given as follows:

Phytoplankton biomass A (mg $\mathrm{CHA} / \mathrm{l})$

$\mathrm{dA} / \mathrm{dt}=\mathrm{Q} / \mathrm{V} \cdot\left(\mathrm{A}_{\text {in }}-\mathrm{A}_{\text {out }}\right)+\mathrm{G}-\mathrm{UA} \cdot \mathrm{A} \cdot \mathrm{f}-\mathrm{FRZ} \cdot \mathrm{Z} \cdot \mathrm{A} \cdot \mathrm{CR}-\mathrm{RESP} \cdot \mathrm{TEMP} \cdot \mathrm{A}$

P-remobilisation from sediment Psed(mg P/l)

$\mathrm{dPsed} / \mathrm{dt}=\mathrm{phi} \cdot \mathrm{hs} \cdot\left(-\mathrm{Dsp} /\left(1-\log \left(\mathrm{phi}^{2}\right)\right) \cdot(\mathrm{P}-(\mathrm{Psed} /(\mathrm{hs} \cdot \mathrm{phi}))) /(\mathrm{hs} / 2)\right.$

$+\quad \Theta($ cpcrit - cpEA)/cpcrit·KFe·cp·qp),

where $\Theta=1$ if cpEA $\leq$ cpcrit and $\Theta=0$ otherwise

Phosphate phosphorus $\mathbf{P}(\mathrm{mg} \mathrm{P} / \mathrm{l})$

$\mathrm{dP} / \mathrm{dt}=\mathrm{Q} / \mathrm{V} \cdot\left(\mathrm{P}_{\text {in }}-\mathrm{P}_{\text {out }}\right)+\mathrm{FRZ} \cdot \mathrm{A} \cdot \mathrm{Z} \cdot \mathrm{CR} \cdot((1-\mathrm{AZP}) \cdot \mathrm{KSA} /(\mathrm{KSA}+\mathrm{A}))$

$+\quad$ RESP.TEMP·A $-\mathrm{G}+(1 / 4) \cdot \mathrm{dPsed} / \mathrm{dt}$

Ammonia nitrogen NH4-N (mg N/l)

$\mathrm{dNH} 4 / \mathrm{dt}=\mathrm{Q} / \mathrm{V} \cdot\left(\mathrm{NH} 4_{\text {in }}-\mathrm{NH} 4_{\text {out }}\right)+\mathrm{B}_{3} \cdot \mathrm{NORG}_{\text {in }}-\mathrm{B}_{1} \cdot \mathrm{NH} 4-\mathrm{FA} 1 \cdot \mathrm{FUP} \cdot \mathrm{G}$

Nitrite nitrogen NO2-N (mg N/l)

$\mathrm{dNO} 2 / \mathrm{dt}=\mathrm{Q} / \mathrm{V} \cdot\left(\mathrm{NO} 2_{\text {in }}-\mathrm{NO} 2_{\text {out }}\right)+\mathrm{B}_{1} \cdot \mathrm{NH} 4-\mathrm{B}_{2} \cdot \mathrm{NO} 2$

Nitrate nitrogen NO3-N (mg N/l)

$\mathrm{dNO} 3 / \mathrm{dt}=\mathrm{Q} / \mathrm{V} \cdot\left(\mathrm{NO} 3_{\text {in }}-\mathrm{NO} 3\right)-(1-\mathrm{FUP}) \cdot \mathrm{FA} 1 \cdot \mathrm{G}+\mathrm{B}_{2} \cdot \mathrm{NO} 2$

Filtrating zooplankton $\mathbf{Z}(\mathrm{mg} \mathrm{C} / \mathrm{l})$

$\mathrm{dZ} / \mathrm{dt}=\mathrm{Q} / \mathrm{V} \cdot\left(\mathrm{Z}_{\text {in }}-\mathrm{Z}_{\text {out }}\right)+\mathrm{FRZ} \cdot \mathrm{A} \cdot \mathrm{Z} \cdot \mathrm{CR} \cdot \mathrm{AZP} \cdot \mathrm{C} \cdot \mathrm{KSA} /(\mathrm{KSA}+\mathrm{A})$

- MORT·TEMP.Z

Dissolved oxygen DO $(\mathrm{mg} / \mathrm{l})$

$\mathrm{dDO} / \mathrm{dt}=\mathrm{Q} / \mathrm{V} \cdot\left(\mathrm{DO}_{\text {in }}-\mathrm{DOout}\right)+\mathrm{K}_{2} \cdot\left(\mathrm{DO}_{\mathrm{sat}}-\mathrm{DO}\right)$

$+\left(\mathrm{a}_{3} \cdot \mathrm{G} / \mathrm{A}-\mathrm{a}_{4} \cdot \mathrm{RESP} \cdot \mathrm{TEMP}\right) \cdot \mathrm{A}-\mathrm{K}_{1} \cdot \mathrm{BOD}-\mathrm{K}_{4} / \mathrm{zmix}$

$-\mathrm{a}_{5} \cdot \mathrm{B}_{1} \cdot \mathrm{NH} 4-\mathrm{a}_{6} \cdot \mathrm{B}_{2} \cdot \mathrm{NO} 2-\mathrm{a}_{7} \cdot \mathrm{MORT} \cdot \mathrm{TEMP} \cdot \mathrm{Z}$

Biochemical oxygen demand BOD $(\mathrm{mg} / \mathrm{l})$

$\mathrm{dBOD} / \mathrm{dt}=\mathrm{Q} / \mathrm{V} \cdot\left(\mathrm{BOD}_{\text {in }}-\mathrm{BOD}_{\text {out }}\right)+\mathrm{K}_{1} \cdot \mathrm{BOD}-\mathrm{K}_{3} \cdot \mathrm{BOD}$

According to [13] temperature dependencies of physical water quality variables are modelled by sinusoidal functions. The saturation concentration of DO is expressed by a third order polynomial [14]. 


\section{The optimisation tool ISSOP}

A software tool ISSOP was developed in [9] to support manufacturing, organisational and logistic processes. It includes an optimisation interface of MATLAB models. The ISSOP architecture of discrete optimisation methods used is shown in fig. 5. The dialogue between external and internal models and optimisation methods is realised by a universal parameter interface. The following optimisation methods are included: CENUM - component wise enumeration, DISOPT - a quasi-gradient method, EVOL - an evolutionary optimisation strategy, SIMCARLO - optimisation by Monte Carlo method, SIMGEN - optimisation by a genetic algorithm. Other optimisation procedures can be added. Before starting an optimisation run each simulation problem is automatically transformed into the standard problem of optimisation. On the lowest level of this architecture simulation models, goal functions and internal process models are given explicitly. External static and dynamic simulation models can be implemented without any restriction. Convexity of goal functions is not necessary.

The coupling of HavelMod with the optimisation tool ISSOP was realised by using the implemented universal open interface. Input variables of the simulation system are denoted by $\alpha_{1} \mathrm{x}_{1}, \ldots, \alpha_{\mathrm{k}} \mathrm{x}_{\mathrm{k}}$, outputs are symbolised by $\mathrm{y}_{1}, \ldots, \mathrm{y}_{\mathrm{m}}$ respectively. Goal functions are denoted by $\mathrm{f}_{1}, \ldots, \mathrm{f}_{\mathrm{n}}$ with $\mathrm{f}_{\mathrm{i}}\left(\mathrm{M}\left(\alpha_{1} \mathrm{x}_{1}, \ldots, \alpha_{\mathrm{k}} \mathrm{x}_{\mathrm{k}}\right)\right)=$ $\mathrm{f}_{\mathrm{i}}\left(\mathrm{y}_{1}, \ldots, \mathrm{y}_{\mathrm{m}}\right)$ where $\mathrm{i}=1, \ldots, \mathrm{n}$, and arbitrary continuous functions can be used. They will be optimised simultaneously. If $n>1$, the goal functions $f_{1}, \ldots, f_{n}$ are aggregated to a weighted sum $\mathrm{S}=\Sigma \mathrm{w}_{\mathrm{i}} \mathrm{f}_{\mathrm{i}}$ with $\Sigma\left|\mathrm{w}_{\mathrm{i}}\right|=1$ and $\mathrm{w}_{\mathrm{i}}$ are weighting factors. ISSOP uses the model variables and target values as input data and gives optimised state variables back to the simulation system.

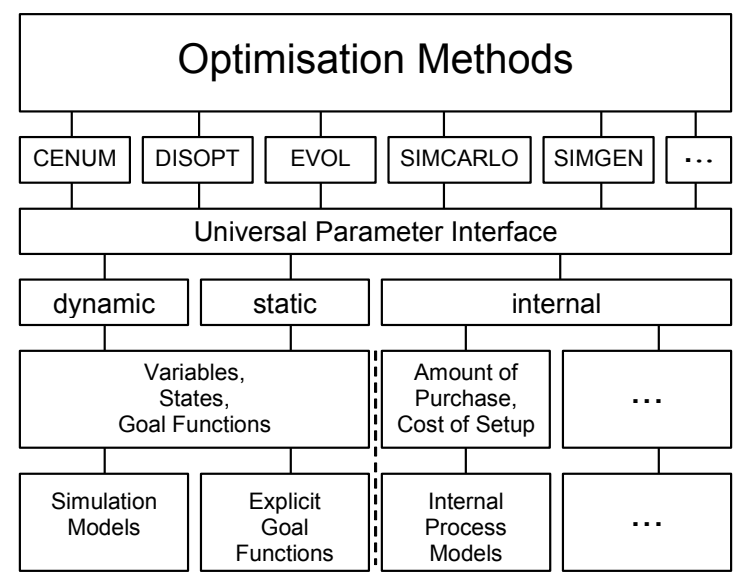

Figure 5: The ISSOP optimisation architecture. 


\section{Experimental area and basic simulations}

The Havel River with its tributary Spree River belongs to the catchment of the Elbe River. Both rivers form a basin which is characterised by small elevation differences between source and mouth, by shallow lakes, wetlands and marshy country, as well as by high evaporation rates. Only $25 \%$ of precipitation contributes to flow. The water quality is mainly influenced by the anthropogenic activities of the urbanised area of Berlin/Potsdam. Time series of water quality data from 1997 are taken into consideration as references, while time series from 1998 to 2002 from different measuring points along the course of the rivers were used for modelling and parameterisation. For water quality simulations the river basin was divided into several segments of different length. After validation procedures the eutrophication simulator was used to carry out basic simulations for the rivers Spree and Havel. Fig. 6 shows results of simulation runs for phytoplankton and for phosphate phosphorus (fig. 7).

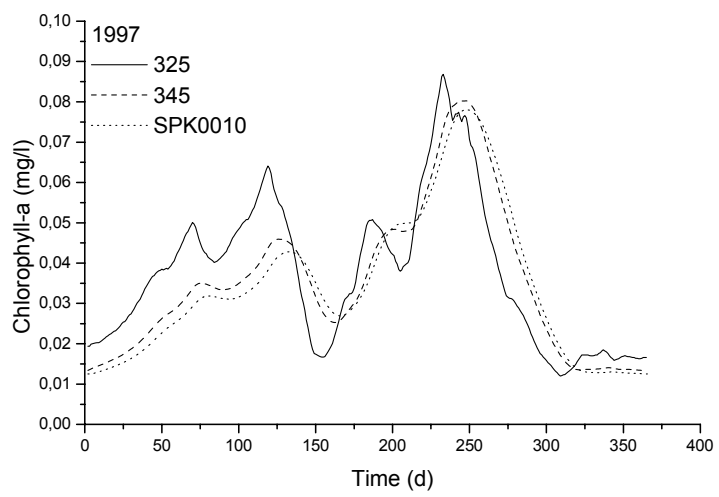

Figure 6: Basic simulation runs for the urbanised area of the river basin.

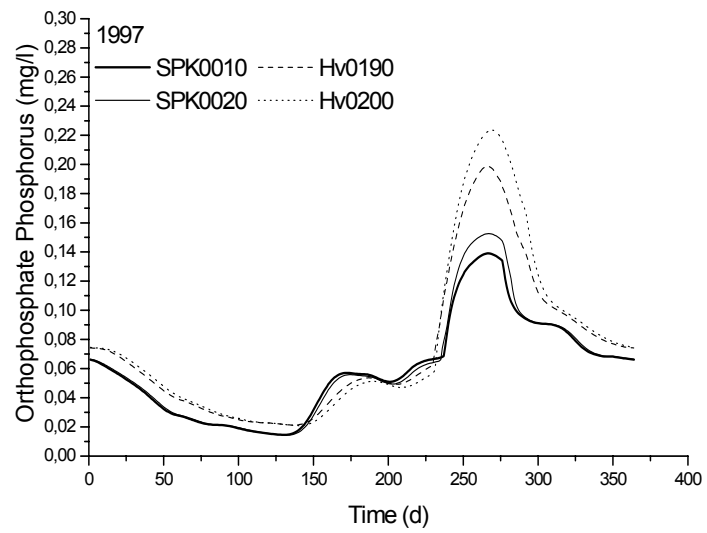

Figure 7: Basic simulation runs for orthophosphate phosphorus. 
The phosphorus dynamics is determined by two different processes: a decrease of phosphate phosphorus due to phytoplankton uptake by diatoms in spring, and an extreme increase due to phosphorus remobilisation from sediment in fall. Because of the nutrient rich water body the bioproduction is high in spring and late summer. During the first four months the growth of diatoms can be seen while in late summer cyanobacteria dominate. In late summer and fall algal blooms collapse and lead to anoxic conditions at the sediment-water interface due to high decay rates of dead organic matter with high rates of oxygen consumption.

\section{Optimisation results}

Two control strategies are taken into consideration. The first one is based on the limiting nutrient concept of algal biomass. The second one refers to the target values of the German Working Group LAWA regulations [15]. Input variables are denoted by $x_{1}$ (phytoplankton biomass), $x_{2}$ (orthophosphate phosphorus) and $x_{3}$ (nitrate nitrogen), output variables $y_{1}, y_{2}$, and $y_{3}$ respectively. To get optimised results for the model transfer function $M\left(\alpha_{1} x_{1}, \alpha_{2} x_{2}, \alpha_{3} x_{3}\right)=\left(y_{1}, y_{2}, y_{3}\right)$ the following goal functions are considered:

1. phytoplankton biomass $f_{l}(t)=\Sigma_{\mathrm{x}} \Sigma_{\mathrm{t}} y_{l}(x, t) \rightarrow \min$.

2. orthophosphate phosphorus $f_{2}(t)=\Sigma_{\mathrm{x}} \Sigma_{\mathrm{t}} y_{2}(x, t) \rightarrow \max$.

3. nitrate nitrogen $f_{3}(t)=\Sigma_{\mathrm{x}} \Sigma_{\mathrm{t}} y_{3}(x, t) \rightarrow \max$.

Corresponding to the input variables following restrictions are valid for the parameters $\alpha_{i}(i=1, . ., 3): \alpha_{1}=1, \alpha_{2}$ and $\alpha_{3}$ vary in the interval $[0,1]$. The results are as follows.

Weights according to the limiting nutrient concept $w_{1}=90.5, w_{2}=-1.1$ and $w_{3}$ $=-8.4$ lead to a diminished phytoplankton maximum in late summer due to optimised nitrate concentrations (fig. 8). No effect of optimised orthophosphate phosphorus concentration can be stated. Optimal averages of goal functions are $f_{1}$ $=44.991 \mu \mathrm{g} / \mathrm{l}, f_{2}=1.472 \mu \mathrm{g} / \mathrm{l}$, and $f_{3}=1.54 \mathrm{mg} / 1$.

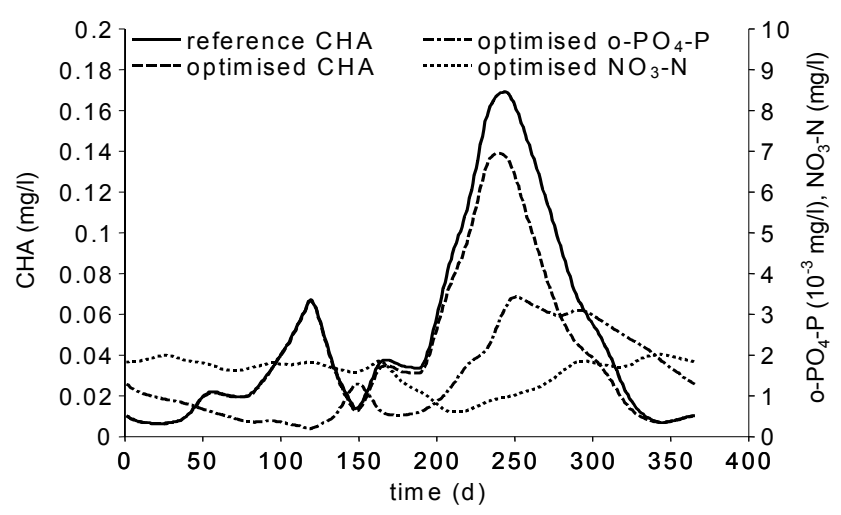

Figure 8: Eutrophication control according to limiting nutrient concept and LAWA regulations. 
Weights according to LAWA $w_{1}=42 \%, w_{2}=-57 \%$ and $w_{3}=-1 \%$ with results $\alpha_{2}=0.03$ and $\alpha_{3}=0.91$ lead to nearly the same behaviour of phytoplankton biomass in spring but to smaller differences of phytoplankton maxima and to low nutrient concentrations in late summer (fig. 9). Optimal averages of goal functions are $f_{1}=48.762 \mu \mathrm{g} / \mathrm{l}, f_{2}=0.166 \mu \mathrm{g} / \mathrm{l}$ and $f_{3}=0.08 \mathrm{mg} / \mathrm{l}$.

In consequence, the LAWA strategy leads to significantly lower nutrient concentrations but to a slight increase of phytoplankton biomass. In eutrophication control by means of limiting nutrient concept results in lower phytoplankton concentrations but higher admissible nutrient inputs.

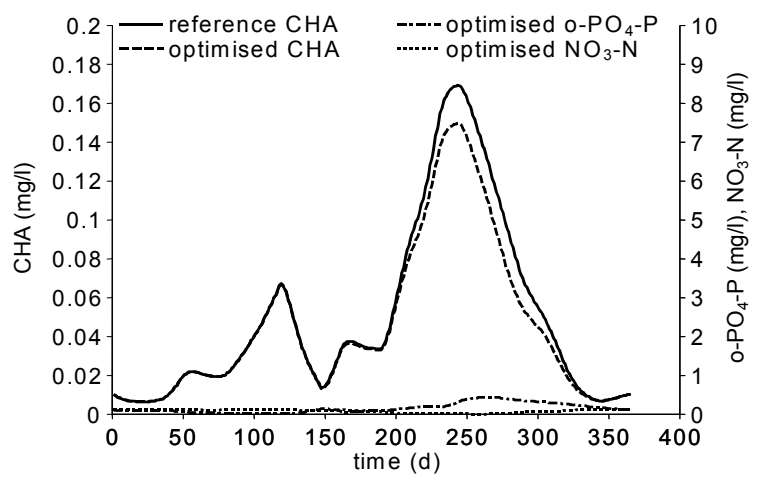

Figure 9: Control of algal biomass according to target values of LAWA.

\section{Conclusions}

A sustainable management to control freshwater ecosystems can only be achieved by using powerful informatic tools. The use of combined simulationoptimisation procedures to manage the water quality of rivers, lakes and reservoirs is an approach promising more theoretical understanding of complicated natural processes and software engineering methods. Phosphate remobilisation from sediment can be considered as a result of some contradictory processes of matter changes. Perspectives of developments of simulation frameworks for water quality management on a river basin scale may be seen in combinations of water quality simulation models, multi-objective optimisation procedures and visualisation tools.

\section{Acknowledgements}

The author is very indebted to Prof. M. Freude from Landesumweltamt Brandenburg for providing the data and to S. Wei and J. D. Alegue for technical assistance. 


\section{References}

[1] Uhlmann, D.: Hydrobiology. Wiley-Interscience, New York, 1975.

[2] Goltermann, H. L. 2004: The Chemistry of Phosphate and Nitrogen Compounds in Sediments. Kluwer, Dordrecht.

[3] DiToro, D. M.: Sediment Flux Modelling. Wiley, Chichester, 2000.

[4] Biswas, A. K. (ed.): Models for Water Quality Management. McGrawHill, New York, 1981.

[5] Wierzbicki, A. P., M. Makowski and J. Wessels (eds.): Model-Based Decision Support Methodology with Environmental Applications. Kluwer, Dordrecht, 2000.

[6] Gnauck, A.: Time Series Analysis of Water Quality Data. In: ScholzReiter, B., H.-D. Stahlmann and A. Nethe (eds.): Process Modelling. Springer, Berlin, 1999, pp. 509-525.

[7] Hoffmann, A.: Mathematical modelling of phosphorus dynamics in rivers with special regard to phosphate remobilization from sediment. Diploma thesis, Dept. of Ecosystems and Environmental Informatics, BTU Cottbus, 1999.

[8] Gnauck A., Heinrich, R. and B. Luther (2002): Water Quality Management of a Sub-Watershed of the Elbe River. In: Pillmann, W. and K. Tochtermann (eds.): Environmental Communication in the Information Society. Internat. Soc. Environm. Protect., Vienna, pp. 524-531.

[9] Krug, W.: Modelling, Simulation and Optimisation for Manufacturing, Organisational and Logistical Processes. SCS Europe Publishing House, Delft, 2002.

[10] Gnauck, A., Luther, B., T. Wiedemann and W. Krug: Coupling of Simulators for Optimal Control of Water Quality. In: Gnauck, A. and R. Heinrich (eds.): The Information Society and Enlargement of the European Union. Metropolis, Marburg, pp. 373-380, 2003.

[11] Gnauck, A. and T. Tesche: Modelling the Sediment-Water Interaction for Riverine Lakes. Internat. Rev. Hydrobiol. 83(1998), Spec. Iss., 207-214.

[12] Reichert, P.: Concepts Underlying a Computer Program for the Identification and Simulation of Aquatic Systems. Dübendorf: Report ETH Zürich/EAWAG, 1994.

[13] Straškraba, M. and A. Gnauck, Freshwater Ecosystems. Elsevier, Amsterdam, 1985.

[14] Thomann, R. V.: Systems Analysis and Water Quality Management. McGraw-Hill, New York, 1972.

[15] LAWA: Beurteilung der Wasserbeschaffenheit von Fließgewässern in der Bundesrepublik Deutschland - Chemische Gewässergüteklassifikation. Kulturbuchverlag, Berlin, 1998. 